\title{
O uso de textos de divulgação científica em atividades didáticas: uma revisão
}

\section{RESUMO}

Márcio César Braga Batistele marcio.batistele@bol.com.br 0000-0001-6738-4182

Universidade Federal de Itajubá, Itajubá-MG

Natália de Paiva Diniz nataliapdiniz@gmail.com 0000-0002-6870-2637

Universidade Federal de Itajubá Itajubá-MG

Jane Raquel Silva de Oliveira janeraquel@unifei.edu.br 0000-0002-7891-5820

Universidade Federal de Itajubá, Itajubá-MG

\begin{abstract}
Neste artigo apresentamos um levantamento de trabalhos desenvolvidos na área de ensino de ciências que reportam o uso de textos de divulgação científica (TDC) em atividades didáticas aplicadas em sala de aula do Ensino Fundamental e do Ensino Médio. A pesquisa, do tipo estado da arte, foi realizada nos anais do Encontro Nacional de Pesquisa em Educação em Ciências e em periódicos nacionais da área de Ensino de Ciências, abrangendo um período de 20 anos. Analisamos nos trabalhos os seguintes aspectos: contextos de aplicação das atividades (nível de ensino, disciplina); objetivos didáticos das atividades; tipos de TDC utilizados; estratégias usadas; e principais contribuições das atividades destacadas pelos autores. Observamos que a maioria das atividades didáticas usa textos de revistas de divulgação científica, adotando principalmente leitura e discussão como estratégias didáticas e estimulando habilidades de leitura, argumentação e aprendizagem de conceitos científicos.
\end{abstract}

PALAVRAS-CHAVE: Texto de divulgação científica. Atividade didática. Revisão bibliográfica. 


\section{INTRODUÇÃO}

Os diversos espaços e materiais de divulgação científica são comumente associados à educação não-formal, a qual pode ser entendida como "qualquer atividade organizada fora do sistema formal de educação, operando separadamente ou como parte de uma atividade mais ampla, que pretende servir a clientes previamente identificados como aprendizes" (MARANDINO, 2008, p.13). Nesse contexto, vários pesquisadores na área de educação em ciências têm se voltado à análise das relações que podem ser estabelecidas entre a educação formal e não-formal, investigando, por exemplo, a influência dos centros e museus de ciências na aprendizagem escolar (MARANDINO, 2001), ou o papel do teatro científico na formação de professores (FRANCISCO JUNIOR et al., 2014), ou as possibilidades e limitações de uso de textos de divulgação científica (TDC) no contexto escolar (FERREIRA; QUEIROZ, 2012a). Segundo Bertoldo et al. (2015),

\footnotetext{
a escola deve considerar todos os gêneros discursivos e, nesse sentido, também o gênero da divulgação da ciência; [...] a educação informal deve fazer parte da educação formal no sentido de uma interação constante, pois o ser humano se educa no seu meio sociocultural (BERTOLDO et al., 2015, p.327).
}

O TDC tem sido considerado uma ferramenta importante a ser utilizada em sala de aula a fim de trazer novas informações e possibilidades para o ensino de ciências (ALMEIDA, 2010; OLIVEIRA, 2013; CARDOSO et al, 2015). Mesmo que os conhecimentos ali comunicados não tenham objetivos didáticos e pedagógicos, os TDC possibilitam que o leitor tenha acesso a informações atualizadas sobre a ciência e a tecnologia, além de apresentarem a forma como esses conhecimentos foram produzidos e não apenas os seus produtos (ROCHA, 2012).

Zamboni (2001) caracteriza o TDC como um texto direcionado a um público não-científico ou não-especialista na área das ciências. Nesse caso, muitas vezes o TDC deixa de lado o rigor do discurso da ciência tornando sua linguagem mais acessível ao leitor ao qual se destina, facilitando a sua compreensão em relação ao conteúdo a ser tratado. Consequentemente, a aproximação da sua linguagem à do leitor pode fazer com que este se interesse mais por conhecer a ciência que está sendo produzida atualmente, não apenas enquanto estudante, mas como cidadão participante da sociedade.

Além disso, as próprias estratégias utilizadas pelos professores, ao trabalharem o TDC em sala de aula, podem trazer uma série de benefícios aos alunos, como o desenvolvimento de habilidade de leitura e argumentação, o domínio de conceitos, o acesso a uma maior diversidade de informações e terminologias científicas etc. (MARTINS et al., 2001; ROCHA, 2012).

Contudo, embora as discussões sobre a importância do uso de TDC em sala sejam frequentes nos estudos da área, o levantamento bibliográfico feito por Ferreira e Queiroz (2012a) aponta que a maioria dos estudos realizados sobre os TDC versam sobre seleção, caracterização e análise de tais materiais. Um percentual bem menor apresenta pesquisas relativas à efetiva implementação desses textos no contexto escolar. Ademais, os trabalhos de revisão bibliográfica localizados pelas autoras também não exploram detalhadamente as pesquisas que reportam atividades em sala de aula envolvendo o uso de TDC. 
Essa questão foi abordada no trabalho de Puiati et al. (2007), os quais buscaram analisar, por meio de um levantamento bibliográfico nas cinco primeiras edições do Encontro Nacional de Pesquisa em Educação em Ciências (ENPEC), como os TDC são usados pelos professores e como este material é utilizado em intervenções didáticas. Os autores destacaram a importância dessa discussão para a área e evidenciaram a necessidade de expandir as pesquisas sobre o uso do TDC em sala de aula.

Dessa forma, percebe-se que a literatura da área carece de dados, sobretudo mais recentes, que nos possibilitem discutir a respeito das ações que têm sido realizadas dentro dessa perspectiva no contexto da educação básica, mais precisamente no âmbito da educação formal de ciências. Ou seja: de que forma um material oriundo da educação não-formal - o TDC - tem sido trabalhado em atividades formais na sala de aula da educação básica? As respostas a essa questão possibilitam aos pesquisadores conhecer o panorama das investigações sobre o uso de TDC que têm sido desenvolvidas no contexto escolar, identificando suas contribuições e lacunas. Possibilitam também ao professor localizar práticas de sala aula realizadas com tais materiais, identificando objetivos, estratégias e recursos possíveis nessa perspectiva.

Neste cenário, apresentamos neste artigo um levantamento de trabalhos desenvolvidos pela comunidade da área de ensino de ciências que reportam o uso de TDC em atividades didáticas aplicadas na sala de aula do Ensino Fundamental (EF) e do Ensino Médio (EM), a fim de conhecer quais os objetivos, estratégias e tipos de TDC são utilizados pelos professores nessas atividades, bem como suas contribuições para a educação em ciências.

\section{PERCURSO METODOLÓGICO}

Esta pesquisa é do tipo estado da arte, a qual se caracteriza por mapear e discutir produções acadêmicas de uma determinada temática - neste caso o uso de TDC em um contexto formal de ensino de ciência - em diversos campos de conhecimento (FERREIRA, 2002; ROMANOWSKI; ENS, 2006). Com isso, busca-se examinar aquilo que já foi elaborado nessas pesquisas e apontar os enfoques dados pelos pesquisadores, as abordagens mais utilizadas, bem como as lacunas ainda existentes. Para isso, é necessário verificar as produções "em diferentes épocas e lugares" (FERREIRA, 2002, p. 258), a fim de traçar um panorama variado do que vem sendo produzido.

O levantamento das produções foi realizado em duas fontes de busca:

a) os anais de todas as edições do ENPEC, realizadas no período de 1997 (primeira edição) a 2015. Esse evento é bienal e vem se estabelecendo como um dos principais espaços para apresentação e discussão de pesquisas na área. Os trabalhos nele publicados possibilitam conhecer de forma panorâmica a produção acadêmica da área de educação em ciências no Brasil.

b) as revistas nacionais da área de ensino de ciências, listadas na classificação dos periódicos realizada pelo chamado Qualis da CAPES para a área de Ensino, com conceito A1, A2 ou B1, com ano de base 2016. Devido aos objetivos desta pesquisa, foram excluídos os periódicos da área de ensino de matemática. Além disso, selecionamos prioritariamente revistas cujo foco editorial contempla especificamente pesquisas na área de ensino de ciências. Dessa forma, 
selecionamos para essa busca as seguintes revistas: Acta Scientiae (A2), Alexandria: Revista em Educação em Ciência e Tecnologia (B1), Areté - revista amazonense de ensino de ciências (A2), Caderno Brasileiro de Ensino de Física (B1), Ciência e Educação (A1), Ciência e Ensino (B1), Ciência em Tela (B1), Debates em educação científica e tecnológica (B1), Educação e Pesquisa (A1), Ensaio: Pesquisa em Educação em Ciências (A2), Experiências em Ensino de Ciências (B1), Investigações em Ensino de Ciências (A2), Pesquisa em Educação Ambiental (B1), Rencima - revista de ensino de ciências e matemática (A2), Revista Brasileira de Ensino de Química (B1), Revista de educação, Ciências e Matemática (A2), Revista Brasileira de Ensino de Ciência e Tecnologia (A2), Revista Brasileira de História da Ciência (B1), Revista Brasileira de Pesquisa em Educação em Ciências - RBPEC (A2), Ensino de ciências e tecnologia em revista (B1), Química Nova na Escola (B1), Caderno Catarinense de Física (cessou em 2001), posterior como Caderno Brasileiro de Ensino de Física (B1), Tear - revista de educação em ciência e tecnologia (B1). O levantamento abrangeu todos os números publicados nesses periódicos entre 1997 e 2016, considerando a disponibilidade dos artigos nos sites de cada revista. Esse recorte deve-se ao fato de que, em revisões bibliográficas realizadas por outros autores, verificou-se que o número de publicações sobre divulgação científica no ensino de ciências passou a crescer de forma mais expressiva a partir de 2000 (NASCIMENTO; REZENDE JUNIOR, 2010; FERREIRA; QUEIROZ, 2012a). Dessa forma, considerou-se que a abrangência de um período de 20 anos forneceria dados significativos para este estudo.

Foram selecionados trabalhos que atendessem aos seguintes critérios: ser trabalho completo de evento ou artigo de revista; reportar o uso de TDC em alguma atividade didática aplicada em sala aula (âmbito formal de ensino); e ter sido aplicado na educação básica (EM e EF). É importante destacarmos que, devido aos critérios pré-estabelecidos, trabalhos que reportam o uso do TDC em situações não-formais de ensino ou que foram aplicados no ensino superior, por exemplo, não foram incorporados no corpus analítico.

Os trabalhos foram inicialmente localizados nos sites do evento por meio de palavras-chave tais como: texto, texto de divulgação científica, artigo de divulgação científica, revista de divulgação científica, texto jornalístico, texto em sala de aula e, também, sala de aula. Em seguida, realizou-se a leitura do título e resumo a fim de verificar se estes atendiam aos critérios de seleção. Para as revistas, optou-se por fazer a busca em cada volume publicado, identificando no título palavras como: texto, texto de divulgação científica, artigo de divulgação científica, revista de divulgação científica, texto jornalístico. Em seguida, realizouse a leitura do resumo. Em ambos os casos, quando necessário, fazia-se a leitura completa do trabalho para verificar se tratavam de uso de TDC aplicado no contexto escolar da educação básica.

Os trabalhos selecionados foram analisados com base nas seguintes questões norteadoras:

a) Quais os contextos de aplicação das atividades (tipo de sistema de ensino, nível de ensino, disciplina)?

b) Quais os objetivos didáticos das atividades mencionados pelos autores?

c) Quais os tipos de materiais didáticos (TDC) usados nas atividades?

d) Quais as principais estratégias usadas em atividades dessa natureza? 
e) Quais as principais contribuições das atividades destacadas pelos autores?

f) Que dificuldades foram apontadas pelos autores na aplicação das atividades?

Adotamos como metodologia de análise dos textos a Análise de Conteúdo (BARDIN, 2008). Realizamos uma leitura flutuante nos textos, buscando localizar unidades de análise relacionadas às questões norteadores, descritas anteriormente. As unidades de análise identificadas nos trabalhos foram classificadas nas seguintes categorias pré-definidas na pesquisa: tipo de sistema de ensino, nível de ensino, disciplina, objetivo didático citado pelos autores, tipo de TDC, estratégias usadas, contribuições das atividades, dificuldades para aplicação das atividades. Dessa forma, dentro da categoria tipo de TDC, por exemplo, foram identificadas unidades como texto de revista de divulgação científica, livro de divulgação científica, texto de divulgação científica publicado em jornal etc.

\section{RESULTADOS E DISCUSSÃO}

$\mathrm{Na}$ busca realizada foram identificados 23 trabalhos que atendiam aos critérios de seleção. Destes, oito foram publicados nas atas dos ENPEC e 15 nas revistas da área de ensino de ciências. Esses trabalhos estão listados por ano de publicação no Quadro 1. Cada trabalho recebeu uma numeração, a qual foi adotada para mapear os aspectos analisados ${ }^{1}$.

Cabe destacar que este número de trabalhos não expressa toda produção acadêmica da área, uma vez que não estão incluídas no levantamento, por exemplo, as teses e dissertações, bem como outros eventos específicos de cada subárea do ensino (ensino de química, ensino de física etc.). Além disso, é digno de nota que estudos de caráter bibliográfico como este, que buscam conhecer atividades aplicadas em sala de aula, não conseguem abarcar as inúmeras propostas implementadas por professores no cotidiano escolar que, em muitos casos, permanecem anônimas ou pouco divulgadas junto à comunidade acadêmica. Em geral, apenas propostas didáticas articuladas a trabalhos de caráter acadêmico costumam ser publicadas nas revistas e eventos da área de pesquisa em ensino de ciência, como é o caso das fontes bibliográficas selecionadas para este estudo.

Quadro 1 - Trabalhos que reportam o uso de TDC em atividades didáticas na sala de aula da educação básica, publicados nos anais do ENPEC (1997 a 2016) e em revistas da área de ensino de ciências (1997 a 2016).

\begin{tabular}{|c|c|l|l|l|}
\hline no & Ano & \multicolumn{1}{|c|}{ Fonte } & \multicolumn{1}{|c|}{ Título } & \multicolumn{1}{c|}{ Autores } \\
\hline 1 & 2001 & $\begin{array}{l}\text { Caderno } \\
\text { Catarinense } \\
\text { de Ensino de } \\
\text { Física }\end{array}$ & $\begin{array}{l}\text { A Natureza da Luz: uma atividade } \\
\text { com textos de divulgação científica } \\
\text { em sala de aula }\end{array}$ & $\begin{array}{l}\text { SILVA, J. A.; } \\
\text { KAWAMURA, M. R. } \\
\text { D. }\end{array}$ \\
\hline 2 & 2003 & IV ENPEC & $\begin{array}{l}\text { Textos de divulgação científica em } \\
\text { sala de aula para o ensino de Física }\end{array}$ & $\begin{array}{l}\text { MONTEIRO M. A. A.; } \\
\text { CASTRO MONTEIRO, } \\
\text { I. C. C.; GASPAR, A. }\end{array}$ \\
\hline 3 & 2004 & $\begin{array}{l}\text { Investigações } \\
\text { em Ensino de } \\
\text { Ciências }\end{array}$ & $\begin{array}{l}\text { Clonagem na sala de aula: um } \\
\text { exemplo do uso didático de um texto } \\
\text { de divulgação científica }\end{array}$ & $\begin{array}{l}\text { MARTINS, I.; } \\
\text { NASCIMENTO, T. G.; } \\
\text { ABREU, T. B. }\end{array}$ \\
\hline
\end{tabular}




\begin{tabular}{|c|c|c|c|c|}
\hline no & Ano & Fonte & Título & Autores \\
\hline 4 & 2007 & VI ENPEC & $\begin{array}{l}\text { Textos de divulgação científica em } \\
\text { aulas de Física: uma abordagem } \\
\text { investigativa }\end{array}$ & $\begin{array}{l}\text { MENEGAT, T. M. C.; } \\
\text { CLEMENT, L.; } \\
\text { TERRAZZAN, E. A. }\end{array}$ \\
\hline 5 & 2008 & $\begin{array}{l}\text { Ensaio: } \\
\text { Pesquisa em } \\
\text { Educação em } \\
\text { Ciências }\end{array}$ & $\begin{array}{l}\text { Leitura coletiva de um texto de } \\
\text { literatura infantil no Ensino } \\
\text { Fundamental: algumas mediações } \\
\text { pensando o ensino das Ciências }\end{array}$ & $\begin{array}{l}\text { GIRALDELLI, C. G. C. } \\
\text { M.; ALMEIDA, M. J. } \\
\text { P. M. }\end{array}$ \\
\hline 6 & 2009 & VII ENPEC & $\begin{array}{l}\text { Literatura na Física: uma possível } \\
\text { abordagem para o ensino de } \\
\text { Ciências? }\end{array}$ & $\begin{array}{l}\text { GUERRA, A.; } \\
\text { MENEZES, A. M. S. }\end{array}$ \\
\hline 7 & 2010 & $\begin{array}{l}\text { Ciência \& } \\
\text { Educação }\end{array}$ & $\begin{array}{l}\text { O uso de textos de divulgação } \\
\text { científica para o ensino de conceitos } \\
\text { sobre Ecologia a estudantes da } \\
\text { Educação Básica }\end{array}$ & $\begin{array}{l}\text { PERTICARRARI, A.; } \\
\text { TRIGO, F. R.; } \\
\text { BARBIERI, M. R.; } \\
\text { COVAS, D. T. }\end{array}$ \\
\hline 8 & 2010 & $\begin{array}{l}\text { Investigações } \\
\text { em Ensino de } \\
\text { Ciências }\end{array}$ & $\begin{array}{l}\text { Leitura de textos de Ciência de } \\
\text { diferentes gêneros: um olhar } \\
\text { cognitivo-processual }\end{array}$ & $\begin{array}{l}\text { NIGRO, R. G.; } \\
\text { TRIVELATO, S. L. F. }\end{array}$ \\
\hline 9 & 2011 & VIII ENPEC & $\begin{array}{l}\text { Uso de texto de divulgação científica } \\
\text { na educação sexual de adolescentes }\end{array}$ & $\begin{array}{l}\text { CIRNE, A. D. P. P.; } \\
\text { TORRES, D. F.; } \\
\text { COSTA, E. S. A.; } \\
\text { ARAÚJO-DE- } \\
\text { ALMEIDA, E.; COSTA, } \\
\text { I. A. S. }\end{array}$ \\
\hline 10 & 2011 & $\begin{array}{l}\text { Ciência \& } \\
\text { Educação }\end{array}$ & $\begin{array}{l}\text { Aproximación didáctica a la } \\
\text { termodinâmica con modelos y } \\
\text { literatura de ciencia ficción }\end{array}$ & $\begin{array}{l}\text { ZAMORANO, R. O.; } \\
\text { MORO, L. E.; GIBBS, } \\
\text { H. M. }\end{array}$ \\
\hline 11 & 2013 & IX ENPEC & $\begin{array}{l}\text { Uma leitura de divulgação científica } \\
\text { sobre ressonância magnética no } \\
\text { Ensino Médio }\end{array}$ & $\begin{array}{l}\text { SILVA A. C.; } \\
\text { ALMEIDA, M. J. P. M. }\end{array}$ \\
\hline 12 & 2013a & IX ENPEC & $\begin{array}{l}\text { Educação ambiental e divulgação } \\
\text { científica: o papel da mídia na } \\
\text { difusão de conhecimentos científicos }\end{array}$ & $\begin{array}{l}\text { ROCHA, M. B.; } \\
\text { NICODEMO, J. F. O. }\end{array}$ \\
\hline 13 & 2013 & IX ENPEC & $\begin{array}{l}\text { Uso de textos de divulgação no } \\
\text { desenvolvimento de temas de } \\
\text { Educação em Saúde na Educação de } \\
\text { Jovens e Adultos (EJA) }\end{array}$ & $\begin{array}{l}\text { LOIOLA, L.; ZANCUL, } \\
\text { M. S.; BIZERRIL, M. } \\
\text { X. A. }\end{array}$ \\
\hline 14 & 2013 & $\begin{array}{l}\text { Experiências } \\
\text { em Ensino de } \\
\text { Ciências }\end{array}$ & $\begin{array}{l}\text { Contando histórias em aulas de } \\
\text { ciências biológicas }\end{array}$ & $\begin{array}{l}\text { SANTOS, L. F. A.; } \\
\text { ZANOTELLO, M. }\end{array}$ \\
\hline 15 & 2013b & $\begin{array}{l}\text { Ensino de } \\
\text { Ciências e } \\
\text { Tecnologia em } \\
\text { Revista } \\
\end{array}$ & $\begin{array}{l}\text { O papel da divulgação científica na } \\
\text { difusão de conhecimentos } \\
\text { ambientais na educação básica }\end{array}$ & $\begin{array}{l}\text { ROCHA, M. B.; } \\
\text { NICODEMO, J. F. O. }\end{array}$ \\
\hline 16 & 2014 & $\begin{array}{l}\text { Educação e } \\
\text { Pesquisa }\end{array}$ & $\begin{array}{l}\text { A revista Ciência Hoje das Crianças } \\
\text { no letramento escolar: a } \\
\text { retextualização de artigos de } \\
\text { divulgação científica }\end{array}$ & $\begin{array}{l}\text { ALMEIDA, S. A.; } \\
\text { GIORDAN, M. }\end{array}$ \\
\hline 17 & 2014 & $\begin{array}{l}\text { Alexandria: } \\
\text { Revista de } \\
\text { Educação em } \\
\text { Ciência e } \\
\text { Tecnologia }\end{array}$ & $\begin{array}{l}\text { A leitura por alunos do Ensino Médio } \\
\text { de um texto considerado de alto grau } \\
\text { de dificuldade }\end{array}$ & $\begin{array}{l}\text { SILVA, A. C.; } \\
\text { ALMEIDA, M. J. P. M. }\end{array}$ \\
\hline
\end{tabular}




\begin{tabular}{|c|c|c|c|c|}
\hline $\mathrm{n}$ 응 & Ano & Fonte & Título & Autores \\
\hline 18 & 2014 & $\begin{array}{l}\text { Experiências } \\
\text { em Ensino de } \\
\text { Ciências }\end{array}$ & $\begin{array}{l}\text { Leitura e produção escrita no ensino } \\
\text { de física como meio de produção de } \\
\text { conhecimentos }\end{array}$ & SETLIK, J.; HIGA, I. \\
\hline 19 & 2014 & $\begin{array}{l}\text { Acta } \\
\text { Scientiae }\end{array}$ & $\begin{array}{l}\text { Argumentação no ensino de Química: } \\
\text { textos de divulgação científica } \\
\text { desencadeando debates }\end{array}$ & $\begin{array}{l}\text { FATARELI, E. F.; } \\
\text { FERREIRA, L. N. A.; } \\
\text { QUEIROZ, S. L. }\end{array}$ \\
\hline 20 & 2015 & X ENPEC & $\begin{array}{l}\text { Análise do potencial didático do livro } \\
\text { de ficção científica no Ensino de } \\
\text { Ciências }\end{array}$ & $\begin{array}{l}\text { BORIM, D. C. D. E; } \\
\text { ROCHA, M. B. }\end{array}$ \\
\hline 21 & 2015 & $\begin{array}{l}\text { Ciência \& } \\
\text { Educação }\end{array}$ & $\begin{array}{l}\text { Monteiro Lobato em aulas de } \\
\text { ciências: aproximando ciência e } \\
\text { literatura na educação científica }\end{array}$ & $\begin{array}{l}\text { GROTO, S. R.; } \\
\text { MARTINS, A. F. P. }\end{array}$ \\
\hline 22 & 2016 & $\begin{array}{l}\text { Caderno } \\
\text { Brasileiro de } \\
\text { Ensino de } \\
\text { Física } \\
\end{array}$ & $\begin{array}{l}\text { O estudo das ondas sonoras por meio } \\
\text { de uma atividade didática } \\
\text { envolvendo leitura de um texto de } \\
\text { divulgação científica }\end{array}$ & $\begin{array}{l}\text { CORREIA, D.; BOLFE, } \\
\text { M. A.; SAUERWEIN, } \\
\text { I.P. S. }\end{array}$ \\
\hline 23 & 2016 & RBPEC & $\begin{array}{l}\text { A apropriação do gênero de } \\
\text { divulgação científica pelas crianças: } \\
\text { fragmentos de um percurso }\end{array}$ & $\begin{array}{l}\text { ALMEIDA, S. A.; } \\
\text { GIORDAN, M. }\end{array}$ \\
\hline
\end{tabular}

Quanto à distribuição temporal dos trabalhos (Figura 1), verificou-se que no período de 1997 a 2000 não foram publicadas pesquisas dessa natureza no corpus analisado. Algumas poucas pesquisas sobre o uso de TDC em sala de aula foram reportadas no período de 2001 a 2009, aparecendo, em geral, apenas uma publicação por ano. Os anos de 2013 e 2014 foram aqueles que mais apresentaram trabalhos nessa temática. Esses dados revelam que os estudos envolvendo a aplicação de TDC no cenário escolar vêm crescendo timidamente na área, evidenciando a necessidade de mais pesquisa nesta perspectiva. Ferreira e Queiroz (2012a) chamam a atenção para o fato de que há um número mais expressivo de publicações na área de ensino de ciências que versam sobre a seleção, caracterização e análise de TDC em relação àqueles que reportam pesquisas sobre a aplicação deste material no contexto da sala de aula.

Figura 1 - Distribuição temporal dos trabalhos que reportam o uso de TDC em atividades didáticas na sala de aula da educação básica, publicados nos anais do ENPEC (1997 a 2016) e em revistas da área de ensino de ciências (1997 a 2016).

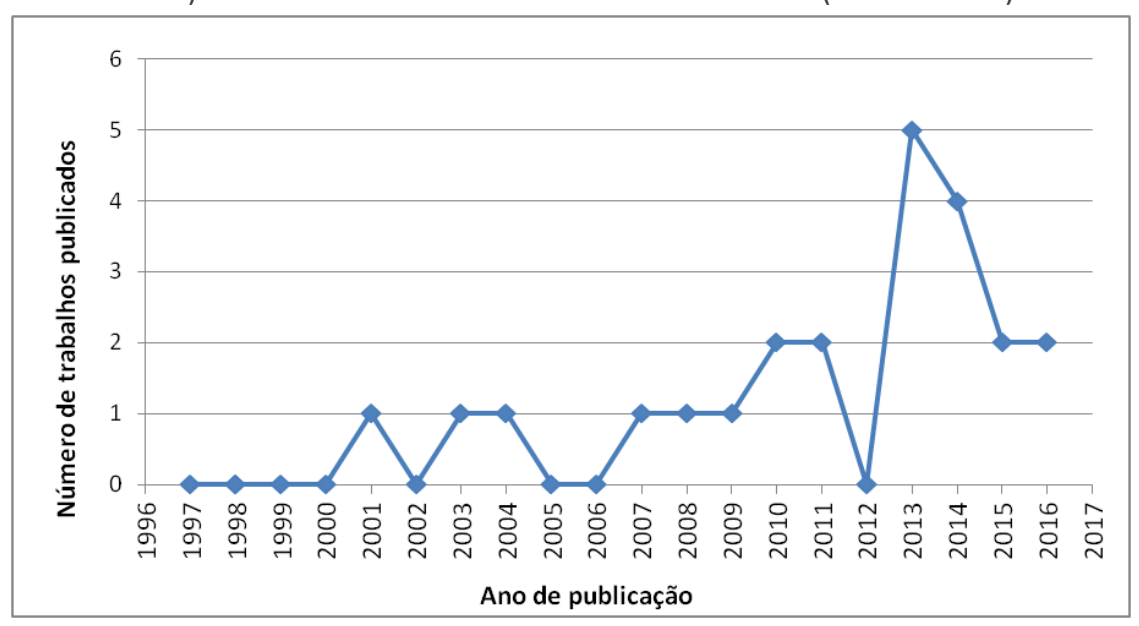

(Fonte: autores) 
Apresenta-se a seguir o mapeamento dos aspectos analisados em cada um dos trabalhos, segundo as questões norteadoras já apresentadas.

a) Contexto de aplicação das atividades didáticas

Inicialmente foram analisados os contextos formais de ensino em que cada trabalho foi desenvolvido, buscando identificar se as atividades didáticas foram aplicadas em escolas públicas ou particulares, se estas envolviam alunos do EM ou EF e em quais disciplinas foram desenvolvidas. Cabe destacar que um mesmo trabalho pode ser representado mais de uma vez por se encaixar em mais de um dos aspectos identificados.

Em relação ao sistema de ensino no qual as atividades foram aplicadas, os dados destacados na Tabela 1 evidenciam a predominância das atividades em escolas públicas (85,7\%), abrangendo turmas do EF e do EM, além de turmas de educação de jovens e adultos (EJA). Esse dado pode estar relacionado a uma maior liberdade dos professores de escolas públicas em implementar propostas didáticas diferenciadas no ensino. Por outro lado, as redes particulares, devido à natureza do sistema, selecionam, em muitos casos, apenas os recursos mais tradicionais, como por exemplo, apostilas ou livros didáticos. Contudo, foi possível encontrar trabalhos que realizaram atividades com TDC na rede particular de ensino, totalizando $28,6 \%$ das pesquisas, o que aponta a preocupação dos educadores em trabalhar outros materiais que não somente as apostilas padronizadas.

Tabela 1 - Sistemas de ensino nas quais foram aplicadas atividades didáticas com TDC em sala de aula da educação básica.

\begin{tabular}{ccc}
\hline Sistema de ensino & Número do trabalho & $\%$ \\
\hline Rede pública de ensino & $1,2,3,5,6,7,11,12,13,14,15$, & 85,7 \\
& $16,17,18,20,21,22,23$ & \\
Rede particular de ensino & $2,7,8,12,15,19$ & 28,6 \\
Não descreve & $4,9,10$ & 14,3 \\
\hline
\end{tabular}

(Fonte: autores)

Quanto ao nível de ensino (Tabela 2), é possível verificar um número relativamente maior de atividades no EM (71,4 \%) quando comparado ao EF $(47,6 \%)$. A maior frequência de trabalhos realizados no contexto do EM pode estar relacionada com a própria temática do texto utilizado, cujo assunto de ciência tem estreita relação com os conteúdos de disciplinas como Física e Biologia trabalhadas neste nível de ensino. Como exemplo, pode-se citar a pesquisa de Silva e Almeida (trabalho no 17) que usaram TDC em turmas de Física do EM para abordagem do tema ressonância magnética, associando-o à tecnologia e aos conhecimentos da disciplina Física.

Já no EF as escolhas são motivadas pelo desafio em vencer as dificuldades da abordagem de determinadas temáticas nessa etapa de desenvolvimento dos alunos, além de tratar de assuntos articulados ao conteúdo programático de Ciências. Dentre esses trabalhos, podemos citar a atividade realizada por Cirne et

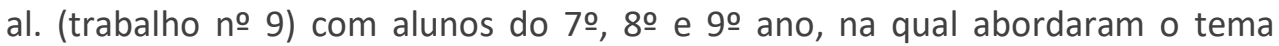
sexualidade, uma vez que, segundo as autoras, tal assunto costuma ser divulgado de forma deturpada e sem respaldo científico pela mídia. 
Tabela 2 - Níveis de ensino nas quais foram aplicadas atividades didáticas com TDC em sala de aula da educação básica.

\begin{tabular}{ccc}
\hline Nível de ensino & № do trabalho & $\%$ \\
\hline Ensino fundamental & $3,5,7,8,9,12,15,16,21,23$ & 47,6 \\
Ensino médio & $1,2,4,6,7,8,10,11,13,14,17$, & 71,4 \\
& $18,19,20,22$ & \\
\hline
\end{tabular}

(Fonte: autores)

Essa estreita relação entre o nível de ensino e a respectiva disciplina na qual as atividades foram aplicadas pode ser reforçada pelos dados apresentados na Tabela 3, que mostra em quais disciplinas cada proposta foi aplicada.

Tabela 3 - Disciplinas nas quais foram aplicadas atividades didáticas com TDC em sala de aula da educação básica.

\begin{tabular}{ccc}
\hline Disciplina & No do trabalho & $\%$ \\
\hline Física (EM) & $1,2,4,6,11,17,18,22$ & 38,1 \\
Biologia (EM) & $7,8,13,14,20$ & 23,8 \\
Ciências (EF) & $3,5,7,8,9,12,15,16,21,23$ & 47,6 \\
Ciências (EM) & 10 & 4,8 \\
Química (EM) & 19 & 4,8 \\
\hline
\end{tabular}

(Fonte: autores)

É possível verificar que $52,4 \%$ dos trabalhos que relatam o uso de TDC no ensino formal foram desenvolvidos na disciplina Ciências - somando-se o EF e EM. É importante mencionar que um dos artigos analisados (trabalho no 10) reporta a aplicação de uma atividade em uma disciplina de Ciências do EM, a qual foi realizada em uma escola da cidade de Mar Del Plata na Argentina com o intuito de abordar a temática Termodinâmica, por meio do uso de textos literários de ficção científica.

Voltando o olhar para as disciplinas específicas do EM, verificou-se que $38,1 \%$ dos trabalhos relatam atividades desenvolvidas na área da Física. Menegat et al. (trabalho no 4) destacaram que o ensino de Física ministrado na Educação Básica costuma ser caracterizado por privilegiar exercícios repetitivos e por apresentar um distanciamento entre conteúdos ensinados e a realidade cotidiana, pouco estimulando esses estudantes a realizarem uma leitura de mundo. Os autores ressaltaram ainda que no EM há uma preocupação para que os alunos se sintam atraídos e motivados em aprender Física, por isso, esperavam que as atividades com TDC oferecessem oportunidade para tal, devido ao modo como esses materiais abordam o conteúdo científico e à própria linguagem utilizada.

De fato, a linguagem presente no TDC parece ser um aspecto que favorece sua inserção no contexto escolar. Conforme Ferreira e Queiroz (2012b), a linguagem empregada na maior parte dos TDC é acessível, oferecendo possibilidades de mediação entre o leitor e o objeto; "quando isso não ocorre ou quando não é possível pela alta densidade discursiva inerente ao discurso científico" (p.39), estratégias são inseridas no texto a fim de facilitar sua compreensão. 
Silva e Kawamura (trabalho no 1), que aplicaram atividades relacionadas com o tema luz em uma turma do 2 o ano do EM, afirmaram que o ensino de Física nas escolas desconsidera as transformações pelas quais o conhecimento passou. Por isso, o TDC pode propiciar outras formas de conhecimentos relativos à ciência, para além dos conceitos científicos em si. A possibilidade de uso de TDC para abordar o processo de construção da ciência é discutida no trabalho de Oliveira (2013), no qual se destaca aspectos como as alianças entre os pesquisadores e as instituições, ênfase às aplicações da pesquisa na esfera social e econômica, destaque às publicações em revistas científicas, a presença de hipóteses e incertezas que surgem durante as pesquisas etc.

As atividades que utilizam TDC aplicadas no ensino de Biologia representam $23,8 \%$ dos trabalhos selecionados. Dentre essas, podemos citar como exemplo o trabalho de Perticarrari et al. (trabalho no 7) que utilizaram um texto de um jornal produzido pela Casa da Ciência de Ribeirão Preto para abordagem de conceitos de ecologia. Os autores apontam que características típicas dos TDC, como a apresentação de pesquisas recentes e a contextualização com o cotidiano das pessoas, favorecem seu uso no ensino de Ecologia. Segundo Zamboni (2001), os TDC têm como característica a apresentação de aspectos de laicidade: recursos discursivos que contextualizam o tema abordado, estabelecendo relações com o cotidiano do leitor. Esses elementos do discurso dos TDC contribuem, portanto, para envolver os alunos com os conteúdos abordados em sala de aula.

Por fim, verificou-se que apenas um dos trabalhos reportou atividade dessa natureza realizada na disciplina de Química, o qual foi descrito por Fatareli et al. (trabalho no 19). Nessa proposta, os autores buscaram aprimorar habilidades de argumentação de estudantes do 20 ano do EM, por meio de debates sobre questões sociocientíficas polêmicas (a produção de energia nuclear) fomentados a partir de TDC da revista Ciência Hoje.

Portanto, identificamos uma carência de trabalhos sobre o uso de TDC em disciplinas de Química da educação básica. Esse dado chama a atenção, uma vez que revela uma lacuna no campo da pesquisa em ensino de ciências e, em particular, no ensino de química. Entretanto, é importante ressaltar que não foram utilizados como fonte de busca os eventos específicos da área de ensino de química, nos quais poderiam ser encontrados trabalhos dessa natureza aplicados no contexto de aulas de química.

b) Objetivos didáticos das atividades mencionados pelos autores

Tendo em vista que o TDC pode ser usado em sala de aula com diferentes intencionalidades, identificaram-se quais os principais objetivos didáticos mencionados pelos pesquisadores nos trabalhos analisados (Tabela 4).

Para Cirne et al. (trabalho no 9), os TDC apresentam uma linguagem próxima de contextos da cultura científica, o que possibilita seu uso como recurso para a aprendizagem de conceitos. Também nessa perspectiva, Zamorano et al. (trabalho no 10) realizaram atividades didáticas utilizando a literatura de fiç̧ão científica com o objetivo de favorecer um melhor entendimento de conceitos da termodinâmica.

A perspectiva de utilização de TDC em sala com o papel de favorecer a aprendizagem de conceitos é discutida no trabalho de Rocha (2012), que buscou 
identificar os principais motivos pelos quais os professores utilizam esses textos em sala de aula. A aprendizagem de conceitos, não só por parte dos alunos, mas para a própria atualização do docente, foi relatada como um dos principais motivos da utilização dos TDC em sala.

Tabela 4 - Objetivos didáticos citados pelos autores nos trabalhos que reportam o uso de TDC em atividades didáticas na sala de aula da educação básica.

\begin{tabular}{ccc}
\hline Objetivos citados pelos autores & Número do trabalho & $\%$ \\
\hline $\begin{array}{c}\text { Favorecer a aprendizagem de } \\
\text { conceitos científicos }\end{array}$ & $\begin{array}{c}1,2,4,5,7,10,12,15,14,20, \\
\text { Desenvolver habilidades de } \\
\text { leitura e interpretação } \\
\begin{array}{c}\text { Despertar curiosidade e } \\
\text { interesse }\end{array}\end{array}$ & $3,4,8,11,16,18,22,23$ \\
$\begin{array}{c}\text { Desenvolver habilidades de } \\
\text { discussão e argumentação }\end{array}$ & $1,3,4,5,9,13,14,17$ & 38,1 \\
$\begin{array}{c}\text { Discutir aspectos da natureza da } \\
\text { ciência }\end{array}$ & 6,21 & 38,1 \\
\hline
\end{tabular}

(Fonte: autores)

Os autores dos trabalhos também mencionaram que as atividades foram realizadas com o objetivo de despertar o interesse e a curiosidade pela ciência (38,1 \%). Giraldelli e Almeida (trabalho no 5), por exemplo, descrevem que a atividade pautada em texto da literatura infanto-juvenil foi planejada com o intuito de aguçar a curiosidade e o interesse das crianças por temas ligados à ciência. Nessa mesma perspectiva, Silva e Almeida (trabalho no 17) trabalharam com TDC da revista Ciência Hoje com o objetivo de despertar a curiosidade e a motivação dos alunos por assuntos da física.

Tais objetivos são coerentes com as colocações de Ribeiro e Kawamura (2011), segundo os quais uma das potencialidades da divulgação científica é possibilitar o encantamento e interesse do público-alvo pela ciência, dando sentido ao conhecimento construído na escola. Segundo as autoras, isso se dá tanto pelo fato do papel da divulgação científica despertar por si só a curiosidade e atrair o leitor para a ciência, quanto pela própria linguagem e forma dos textos, que se diferenciam daqueles com os quais os alunos estão acostumados nas disciplinas de ciência.

As habilidades de leitura e interpretação, consideradas como um dos componentes fundamentais para a alfabetização científica (BERTOLDO et al., 2015), foram mencionadas como objetivo didático em 38,1 \% dos trabalhos. Almeida e Giordan (trabalhos no 16 e № 23), por exemplo, preocupados com a ausência de práticas significativas de leitura na educação em ciências nos primeiros anos da educação básica, utilizaram TDC da revista Ciência Hoje das Crianças em uma atividade com alunos do 4 o ano do EF, com o objetivo de fomentar suas habilidades de leitura.

O desenvolvimento da competência leitora no ensino de ciências é discutido por Francisco Junior (2011), o qual argumenta que os textos propiciam ao estudante não apenas a leitura da palavra, mas também maior criticidade e melhor aprendizagem. Segundo o autor, a leitura de textos proporciona ainda 
habilidades como comparar e relacionar variáveis em uma determinada situação problema, tomar decisões cotidianas, desenvolver a argumentação frente a questões sociais, políticas, econômicas e ambientais, dentre outras habilidades.

Outro objetivo almejado nas atividades foi o desenvolvimento da capacidade de discussão e de argumentação por parte dos alunos, indicado em 33,3 \% dos trabalhos. Sob tal perspectiva, Fatareli et al. (trabalho no 19) promoveram o debate sobre o urânio empobrecido por meio de TDC com o intuito de promover o "desenvolvimento do espírito crítico dos alunos e para a elaboração de argumentações e contra-argumentações" (p. 629).

O desenvolvimento de habilidades de argumentação tem sido um objetivo bastante atrelado à aplicação de TDC na educação em ciências (FERREIRA; QUEIROZ, 2012a), devido à abordagem de temas atuais que impactam de certa forma a vida das pessoas. Podendo até mesmo conter assuntos controversos, os TDC têm o potencial de permitir que o aluno acesse a informação, reflita e tenha um momento para argumentar sobre ela, cabendo ao professor mobilizar estratégias para que essa habilidade possa ser desenvolvida.

\footnotetext{
As avaliações - internacional e nacional - estão sinalizando para a busca de uma aprendizagem mais direcionada à forma de raciocinar em ciências e não como uma simples aquisição de conceitos. E a forma característica do raciocínio científico é aquela em que os enunciados, conclusões, hipóteses ou teorias não constituem meras opiniões, mas devem estar sustentadas em provas, dados empíricos ou respaldo de natureza teórica (SASSERON; CARVALHO, 2011, p.245)
}

Nessa perspectiva, Sasseron e Carvalho (2011) apontam o desenvolvimento da capacidade de argumentação como um objetivo importante para o ensino de ciências e para a formação de professores, pois é necessário que o professor trabalhe para estimular o aparecimento das mesmas na aula.

Os TDC podem ser uma ferramenta didática útil para que os alunos tenham contato com os processos do fazer ciência e não apenas aos seus produtos (ROCHA, 2012), além de possibilitarem a discussão do funcionamento da ciência atual (OLIVEIRA, 2013). No entanto, discutir aspectos da natureza da ciência (NdC) foi um objetivo mencionado em apenas 9,5\% dos trabalhos analisados.

Segundo Guerra e Menezes (trabalho no 6), as leituras de alguns textos literários que abordam temas de ciência favoreceram a construção de imagens sobre a natureza e o funcionamento do trabalho científico. Os autores realizaram uma atividade pautada no uso de TDC procurando abordar questões de natureza histórico-filosófica, apresentando uma ciência que não pronta e acabada, mas em constante construção. Nesta mesma perspectiva, Borim e Rocha (trabalho no 20) trabalharam obras literárias que versam sobre ciência com alunos do EM no intuito de abordar questões relacionadas à NdC.

Esses trabalhos colocam em destaque a importância de levar o debate sobre a NdC para as salas de aulas, explorando possibilidades de se discutir sobre ciência e seu processo de construção, principalmente no sentido de desmistificar concepções estereotipadas da ciência presente no imaginário dos estudantes (GIL-PEREZ et al., 2001).

Diante dos objetivos propostos pelos autores, percebemos que o uso do TDC em sala de aula está muitas vezes associado ao desejo de um ensino que favoreça 
o aprimoramento de conceitos, o envolvimento dos alunos em debates e discussões sobre o conhecimento científico, o desenvolvimento da leitura e da argumentação, a fim de estimular seu envolvimento com a ciência e com o mundo de um modo mais amplo - contribuindo para uma formação cidadã.

Cabe ainda ressaltar que, em geral, muitos dos objetivos didáticos mencionados nesses trabalhos são também explicitados por professores quando questionados sobre o papel dos TDC na educação. Segundo Rocha (2012), para a maioria dos professores, os TDC têm como papel: contribuir para a formação do aluno, melhorando e aumentando seu vocabulário; favorecer a aprendizagem de conceitos; promover troca de ideias entre professor e alunos; possibilitar discussões de questões sociais.

c) Estratégias didáticas usadas nas atividades

São apresentadas na Tabela 5 as principais estratégias didáticas utilizadas nas atividades. Os dados apontam que em todas elas houve a leitura de textos, individuais ou coletivas. Cabe ressaltar que, embora essa estratégia seja adotada em todas as propostas, os autores nem sempre colocam explicitamente como objetivo o desenvolvimento das habilidades de leitura e interpretação, possivelmente por julgarem que o ato de ler em si já estaria associado ao desenvolvimento de tais habilidades. Ademais, Bertoldo et al. (2015) ressaltam ainda que, em muitas escolas, o desenvolvimento de hábitos de leitura é entendido como algo de responsabilidade das aulas de Língua Portuguesa.

Tabela 5 - Estratégias didáticas adotadas nos trabalhos que reportam o uso de TDC em sala de aula.

\begin{tabular}{|c|c|c|}
\hline Estratégia didática & Número do trabalho & $\%$ \\
\hline Leitura de textos & $\begin{array}{l}1,2,3,4,5,6,7,8,9,10,11,12,13 \\
14,15,16,17,18,19,21,20,22,23\end{array}$ & 100 \\
\hline Aplicação de questionários & $\begin{array}{c}1,2,6,7,8,9,10,11,12,13,14,15 \\
17,19,22\end{array}$ & 71,4 \\
\hline $\begin{array}{c}\text { Realização de discussões e } \\
\text { debates }\end{array}$ & $\begin{array}{c}3,4,6,7,9,10,12,13,14,15,19 \\
21,22,23\end{array}$ & 66,7 \\
\hline $\begin{array}{l}\text { Elaboração de perguntas pelos } \\
\text { alunos }\end{array}$ & $1,14,19$ & 14,3 \\
\hline Elaboração de textos & 18,20 & 9,5 \\
\hline $\begin{array}{l}\text { Resolução de problemas } \\
\text { investigativos }\end{array}$ & 4 & 4,8 \\
\hline
\end{tabular}

(Fonte: autores)

Em atividade realizada com um texto da literatura infanto-juvenil, Giraldelli e Almeida (trabalho no 5) aplicaram uma estratégia de leitura coletiva em sala de aula com alunos do EF. As autoras notaram que os sentidos produzidos pelas crianças não se devem unicamente ao próprio texto e que, nesse processo de leitura, os alunos conseguiram reelaborar seus conhecimentos e construir conceitos sobre os assuntos abordados no TDC. Santos e Zanotello (trabalho no 14) aplicaram uma estratégia de leitura, na qual a turma foi dividida em grupos, cada um deles sendo responsável pela leitura e apresentação oral de um capítulo de um livro de DC. Nas aulas subsequentes às apresentações, os estudantes 
construíram relações entre o conteúdo que abordado na disciplina de Biologia e o texto lido.

Tais relatos evidenciam o papel da escola no desenvolvimento das habilidades de leitura e, neste caso, as potencialidades do uso de TDC nessa tarefa. Segundo Giraldi e Cassiani (2009), diferentes textos chegam até às pessoas por uma multiplicidade de meios: livros, revistas, jornais, televisão, outdoors, internet, etc. - todos eles são lugares de produção de sentidos sobre o mundo. Para as autoras, entre tantos espaços em que a produção de sentidos se dá, a escola representa um espaço privilegiado para tal, uma vez que é nela em que os sujeitos são colocados em contato com o conhecimento de forma sistematizada.

Outra estratégia utilizada nas atividades foi a aplicação de questionários $(71,4 \%)$, os quais foram, em geral, utilizados com duas finalidades: diagnóstica, isto é, para verificar os conceitos dos alunos em relação ao conteúdo antes da atividade; e/ou avaliativa, para verificar o que foi aprendido pelos alunos após a leitura/discussão dos textos. Rocha e Nicodemo (trabalhos no 12 e no 15), por exemplo, relataram o uso de um questionário para identificação dos conhecimentos prévios sobre os temas abordados no TDC, bem como para acompanhar a aprendizagem dos alunos e seu desempenho nas atividades aplicadas.

A realização de discussões e/ou debates em sala de aula também foi adotada como estratégia didática em muitos trabalhos (66,7 \%). Segundo Loiola et al. (trabalho $\mathrm{n}$ - 13), nessa estratégia os alunos se mostraram muito reflexivos em relação ao tema abordado nos TDC e curiosos por informações mais específicas sobre o assunto. Para Martins, Nascimento e Abreu (trabalho no 3), os TDC apresentam temáticas que podem ser provocadoras de debates, permitindo um elo com elementos do cotidiano dos estudantes.

A prática do debate em aulas de ciências possibilita que os alunos exponham suas ideias a respeito de conceitos científicos e seus impactos para a sociedade, em um ambiente que os instigue. Altarugio et al. (2010) aponta que o debate como estratégia também propicia o desenvolvimento argumentação, uma vez que os estudantes precisam ser capazes de reconhecer as afirmações contraditórias e aquelas que dão sustentação à suas afirmações.

Também foi adotada como estratégia didática a elaboração de perguntas pelos alunos (14,3\%). Essa estratégia foi observada, por exemplo, no trabalho de Silva e Kawamura (trabalho no 1), no qual foi realizada a elaboração de perguntas em conjunto, por alunos e professor, sobre o TDC adotado na atividade. Segundo as autoras, o ato de perguntar possibilita aos alunos um desequilíbrio em suas estruturas cognitivas e a reestruturação dessas estruturas. Já no trabalho de Santos e Zanotello (trabalho no 14), os alunos foram divididos em grupos, e cada grupo deveria realizar a leitura de um capítulo do TDC, expô-lo aos demais colegas da classe e propor duas questões para os colegas sobre o capítulo lido. A intenção da atividade não era atribuir certo ou errado (tanto às perguntas feitas pelos alunos quanto às respostas dadas pelos colegas), mas propiciar um aprendizado diferente ao habitualmente realizado nas aulas.

A produção de outros gêneros textuais também foi uma estratégia adotada, 
Setlik e Higa (trabalho no 18) verificaram que a produção escrita atuou como um meio de construir relações, expressar e sistematizar conhecimentos a respeito dos conceitos físicos trabalhados em sala de aula. Ressalte-se ainda que a leitura acompanhada da escrita permite ao professor a melhor avaliação sobre as relações estabelecidas entre o texto e o próprio conteúdo da disciplina ou o cotidiano do aluno, isso porque a escrita consolida a compreensão textual por parte dos alunos-leitores, os sentidos apropriados por eles (FRANCISCO JUNIOR, 2011).

Por fim, Menegat et al. (trabalho no 4) adotaram como estratégia didática a resolução de problemas investigativos em aulas de Física por meio de textos de revistas como Globo Ciência e Superinteressante. Foi estabelecida uma situação problema a partir do texto utilizado pelo professor. Em seguida, os alunos foram estimulados a levantar as variáveis envolvidas na situação proposta, bem como estudar parâmetros e possibilidades para a resolução do problema abordado. Segundo os autores, as atividades investigativas favorecem a realização de questionamentos, a elaboração de sínteses e a troca de ideias, colaborando na compreensão dos conceitos físicos.

Percebe-se, portanto, que diversas estratégias podem ser associadas à leitura de TDC em sala de aula. A escolha, conforme observado nos trabalhos, está relacionada, sobretudo, aos objetivos almejados pelo professor. No entanto, convém destacar que a grande maioria dessas estratégias ainda está centrada na leitura e discussão, geralmente acompanhada de algum de tipo de questionário para diagnóstico de conceitos científicos. A produção de outros gêneros textuais a partir do TDC tem sido ainda uma estratégia pouco explorada.

d) Tipos de TDC usados nas atividades didáticas

Na Tabela 6 são apresentados os tipos de TDC adotados nas atividades. De acordo com os resultados, é possível observar que textos das revistas de divulgação científica foram empregados em 57,1 \% dos trabalhos.

Tabela 6 - Tipos de TDC adotados nos trabalhos que reportam seu uso em atividades didáticas na sala de aula.

\begin{tabular}{ccc}
\hline $\begin{array}{c}\text { Tipos de textos de divulgação } \\
\text { científica }\end{array}$ & Número do trabalho & $\%$ \\
\hline $\begin{array}{c}\text { Texto de revista de divulgação } \\
\text { científica }\end{array}$ & $1,2,3,4,8,9,11,13,16,17,19$, & 57,1 \\
Livros de divulgação científica & 22 & 19 \\
Texto de divulgação científica & $1,10,14,20$ & 19 \\
em jornal & $3,7,12,15$ & \\
Obras literárias clássicas & $5,6,21$ & 14,3 \\
Artigo de divulgação científica & 18,22 & 9,5 \\
\hline
\end{tabular}

(Fonte: autores)

Esse dado pode ser atribuído ao fato de que, em geral, as revistas de divulgação científica possuem textos relativamente curtos, de visual atrativo e linguagem mais acessível. Elas publicam trabalhos de uma grande variedade de temas, o que possibilita ao professor escolher aquele que mais se aproxima do currículo escolar ou dos objetivos propostos para a atividade. Além disso, algumas revistas têm seus textos total ou parcialmente disponíveis na Internet, o 
que facilita o acesso por parte de professores e alunos (CAVALCANTE; FARIAS, 2011).

A escolha pela utilização de textos de revistas é justificada por autores como Gomes et al. (2010), que argumentam positivamente a respeito do uso da revista Ciência Hoje, ressaltando sua ótima conceituação dentro da comunidade acadêmica, uma vez que seus artigos são escritos por autores com boa formação científica. Menegat et al. (trabalho no 4) apontam que os textos da revista Superinteressante fornecem aos alunos contato com informações atualizadas da ciência, bem como estabelecem relações com seu cotidiano. Já Almeida e Giordan (trabalhos no 16 e no 23) chamam a atenção para revista Ciência Hoje das Crianças assinalando seu caráter multidisciplinar e aproximação entre pesquisadores e público infantil em geral.

Os TDC, além de informar sobre os conhecimentos produzidos na ciência, também apresentam um caráter educativo, uma vez que adotam estratégias discursivas que buscam facilitar a compreensão do conteúdo científico abordado (ZAMBONI, 2001). Assim, podem ser observados em textos de revistas de divulgação científica alguns traços de didaticidade, os quais envolvem "procedimentos como explicações, recapitulações, orientações metodológicas etc." (FERREIRA; QUEIROZ, 2012b, p.23). Essas características tornam tais materiais potencialmente úteis para utilização no contexto escolar e justificam em parte a escolha dos autores por tais TDC.

Outro recurso utilizado nas atividades foram os textos de jornais que veiculam temas científicos ( $19 \%$ dos trabalhos). Rocha e Nicodemo (trabalhos no 12 e no 15), por exemplo, abordaram o tema aquecimento global por meio da leitura e discussão de uma reportagem publicada no jornal $O$ Globo. Já Martins et al. (trabalho no 3) trabalharam, junto a uma turma de EJA, o tema clonagem por meio de uma reportagem do jornal Extra em conjunto com um artigo da revista Superinteressante.

Esses exemplos evidenciam algumas potencialidades do jornalismo científico na educação em ciências. Segundo Amorim e Massarani (2008), o ensino formal, muitas vezes, é insuficiente para a educação da população como um todo; por isso o jornalismo científico atua como uma forma de difundir conhecimento sobre as inovações, a importância e as incertezas da ciência.

Livros de divulgação científica também foram empregados como recurso didático (19 \%). Silva e Kawamura (trabalho no 1) utilizaram as obras Física Divertida, de Carlos Fiolhais, e A Evolução da Física, de Einstein e Infeld para trabalharem a natureza da luz com alunos na disciplina Física. Santos e Zanotello (trabalho no 14), visando estimular o interesse e a aprendizagem dos alunos, utilizaram como recurso didático o livro Você é um animal, Viskovitz, do autor Alessandro Boffa.

Obras de literatura do gênero ficção científica também foram usadas em algumas atividades, como a La última pergunta, de Isaac Asimov, e Los cristales, de Ítalo Calvino, utilizadas por Zamorano et al. (trabalho no 10) para abordagem de conceitos da Física. Enquanto Borim e Rocha (trabalho no 20) utilizaram a leitura de trechos da obra de fiç̧ão científica Jogador Número 1, de Ernest Cline, para abordar conceitos de educação ambiental. Em ambos os trabalhos, os autores ressaltam que as obras de ficção foram escolhidas por apresentarem 
linguagem atrativa aos alunos e fácil leitura, além de apresentarem uma boa qualidade conceitual.

No âmbito do ensino de Física, por exemplo, Zanetic (1998) destaca que os textos literários são potencializadores da aprendizagem em sala de aula, pois: favorecem a aprendizagem de conceitos e estimulam nos alunos o interesse por temas científicos; possibilitam uma aula dinâmica e com uma perspectiva interdisciplinar; têm impacto direto na própria formação dos professores e no desenvolvimento de novas estratégias didáticas; e, como ponto principal, auxiliam no desenvolvimento do hábito (e do prazer) da leitura.

Além dos livros de divulgação que têm uma temática científica central, também foi possível observar o uso de obras literárias clássicas em 14,3 \% das atividades. Giraldelli e Almeida (trabalho no 5) utilizaram em aula do EF a obra infanto-juvenil Tem um Cabelo na Minha Terra, de Garry Larson, pelo fato de abranger conhecimento biológico, ambiental e literário. Também em aulas de ciências no EF, as obras A reforma da natureza e Serões de Dona Benta, de Monteiro Lobato, foram utilizadas por Groto e Martins (trabalho no 21) na abordagem de conteúdos científicos e de questões acerca da natureza da ciência.

Tais trabalhos mostram que mesmo textos que não são formalmente materiais para divulgação da ciência podem ser trabalhados pelo professor com essa finalidade.

\footnotetext{
Seja como veículo para despertar a imaginação, seja como veículo para contextualizar histórica e filosoficamente o ensino de conceitos científicos, a Literatura é um caminho para se trabalhar ciência na escola. A Literatura abre a possibilidade para o leitor de participar da trama, em determinado cenário histórico e filosófico, dialogando muitas vezes com o autor, despertando sentimentos de empatia. Com isto, a percepção de um processo de conhecer se instaura, rompendo com o conhecimento pronto, acabado, construído por seres especialmente iluminados. Portanto, a Literatura pode favorecer a problematização da ideia de que todo conhecimento, particularmente científico, é construído por gênios, apenas por inspiração. (GUERRA; MENEZES, 2009, p. 09).
}

Por fim, outro recurso utilizado nas atividades foram artigos de divulgação científica que são disponibilizados em outras fontes que não necessariamente revistas de divulgação $(9,5 \%)$, como, por exemplo, o texto utilizado por Setlik e Higa (trabalho no 18) intitulado Dopping Científico, disponível em uma página da internet do Instituto de Física de São Carlos; e o TDC Para Ouvir Melhor, disponível na revista VEJA e utilizado por Correia et al. (trabalho no 22) para abordagem de conceitos de Física.

e) Contribuições das atividades didáticas

Apresentamos na Tabela 7 as principais contribuições reportadas pelos autores em relação ao uso de TDC na educação em ciência, ao discutirem os resultados das atividades didáticas.

De acordo com os dados, é possível verificar que a apropriação de conceitos científicos por parte dos envolvidos nas atividades foi a mais mencionada nos trabalhos (76,2 \%), o que é bastante coerente com os objetivos traçados nas propostas (item b).

Cirne et al. (trabalho no 9) perceberam que as respostas dos alunos em questões de natureza científica foram se moldando ao longo da atividade, 
indicando uma gradativa apropriação de conceitos. Perticarrari et al. (trabalho no 7), ao analisarem as respostas dos alunos em questionários sobre as atividades propostas, identificaram que eles passaram a conhecer determinados conceitos sobre ecologia após a leitura do TDC. Silva e Kawamura (trabalho no 1) também constataram a mudança de concepções nos alunos sobre o tema luz, quando analisaram perguntas feitas pelos mesmos inicialmente e ao término da pesquisa.

Tabela 7 - Contribuições das atividades didáticas que usam TDC em sala de aula da educação básica.

\begin{tabular}{ccc}
\hline Contribuição & Número do trabalho & $\%$ \\
\hline $\begin{array}{c}\text { Apropriação de conceitos } \\
\text { científicos }\end{array}$ & $1,2,3,4,5,7,8,9,10,12,13$, & 76,2 \\
$\begin{array}{c}\text { Desenvolver habilidades de } \\
\text { leitura }\end{array}$ & $1,2,3,4,8,11,20,21,22$ & \\
$\begin{array}{c}\text { Melhoria da capacidade de } \\
\text { argumentação }\end{array}$ & $1,3,4,9,11,13,14,16,22,23$ & 52,4 \\
$\begin{array}{c}\text { Conhecimentos sobre a } \\
\text { natureza da ciência }\end{array}$ & $1,3,6,7,10,21$ & 47,6 \\
$\begin{array}{c}\text { Reconhecimento de concepções } \\
\text { científicas inadequadas }\end{array}$ & $2,10,18$ & 28,6 \\
\hline
\end{tabular}

(Fonte: autores)

O desenvolvimento de habilidades de leitura foi citado pelos pesquisadores em $52,4 \%$ dos trabalhos. Cabe lembrar que todas as atividades adotaram estratégias de leitura, embora somente alguns autores (38,1\%) tenham colocado de forma explícita o desenvolvimento dessas habilidades como objetivo da proposta.

Nigro e Trivelato (trabalho no 8), ao realizarem uma atividade de leitura envolvendo alunos do EF e EM, verificaram que os participantes ficaram mais motivados a desenvolver o hábito da leitura. Almeida e Giordan (trabalhos no 17 e no 23) constataram que a interação das crianças com o TDC contribui tanto para a leitura quanto para a argumentação, principalmente no que diz respeito à forma de falar e escrever a ciência.

\footnotetext{
Trata-se de uma operação em que as crianças necessitam negociar os sentidos, contextualizar as informações, compartilhar conhecimentos e preencher as lacunas implícitas do texto, demonstrando um trabalho de compreensão da leitura dos artigos de divulgação científica (ALMEIDA; GIORDAN, 2014, p. 1011).
}

Além do desenvolvimento da habilidade de leitura, foi reportada em 47,6\% dos trabalhos a melhoria na capacidade de argumentação dos estudantes. Martins et al. (trabalho no 3) consideram as práticas de leitura e discussão de TDC desencadeadoras de debates com alto grau de participação dos alunos, os quais passaram a estabelecer relações entre contextos de informações escolares e extraescolares. Santos e Zanotello (trabalho no 14) verificaram que as relações entre alunos e alunos-professora, durante o compartilhamento das apresentações orais sobre o texto lido, favorecem a argumentação e contribuem para a formação de novos sentidos acerca da leitura e dos conceitos disponíveis no TDC. 
A construção de conceitos sobre a $\mathrm{NdC}$ foi verificada em 28,6 \% dos trabalhos, incluindo alguns que não indicaram previamente tal aspecto como um objetivo da atividade. Guerra e Menezes (trabalho no 6) investigaram uma atividade que abordou aspectos da NdC por meio da relação ciência/literatura. A atividade, segundo as autoras, propiciou aos estudantes reflexão em relação à popular imagem da ciência (pronta, acabada, neutra). Groto e Martins (trabalho no 21) verificaram que trabalhar questões sobre $\mathrm{NdC}$ com obras literárias de Monteiro Lobato possibilitaram a problematização de concepções consideradas inadequadas sobre a ciência, além de estimular a "curiosidade epistemológica" dos estudantes e favorecer o processo de percepção de uma ciência humanizada. Zamorano et al. (trabalho no 10) também apontam que os livros de ficção científica podem auxiliar a desmistificação da ciência dentro do contexto social dos alunos.

Outros tipos de TDC também são apontados na literatura como uma importante ferramenta para trazer discussões sobre a $\mathrm{NdC}$ em sala de sala, como o trabalho de Martins et al. (2001) que utilizou a re-elaboração discursiva de um artigo da revista Ciência Hoje; Oliveira (2013) que analisou aspectos da sociologia da ciência na revista Pesquisa FAPESP; e Gouvêa (2000) com a revista Ciência Hoje das Crianças, apontando que mesmo que os conhecimentos ali comunicados não tenham essa finalidade, eles possibilitam que o leitor tenha acesso a forma como a ciência é produzida.

Por fim, uma contribuição mencionada pelos autores em 14,3 \% dos trabalhos é a possibilidade do professor, dentro do contexto das atividades de leitura, análise e discussão de TDC, identificar as concepções alternativas dos estudantes. Monteiro et al. (trabalho $\mathrm{n}$ ㅇ 2) conseguiram verificar algumas concepções científicas inadequadas, muitas das quais passariam despercebidas em aulas tradicionais. Para os autores, esse tipo de atividade foi significativa para que tais concepções pudessem ser (re)discutidas em sala de aula. Já Setlik e Higa (trabalho no 18) apontam que, através dos textos produzidos pelos alunos, foi possível avaliar e acompanhar a evolução de seus pensamentos, compreendendo melhor a subjetividade de cada um dos estudantes e suas concepções sobre os conceitos estudados, permitindo ao professor trabalhar os conteúdos a partir dessas concepções para mudá-las ou fortalecê-las.

As concepções alternativas estão presentes em alunos de todos os níveis de ensino, sendo importante apresentá-los a questões, problemas ou situações que possam auxiliar na sua desconstrução para a consequente construção do conhecimento científico (KÖHNLEIN; PEDUZZI, 2002). Por isso, seja na educação forma ou não formal, é importante que professores e mediadores estejam preparados para identificar e trabalhar tais ideias.

f) Dificuldades para aplicação das atividades citadas pelos autores

Em nosso último item de análise, buscamos identificar algumas dificuldades que os autores mencionam nas aplicações das atividades pautadas no uso de TDC em sala de aula. Essas informações são relevantes, pois podem auxiliar os professores e/ou pesquisadores no direcionamento de algumas escolhas relacionadas às atividades dessa natureza.

Os resultados apresentados na Tabela 8 indicam que 66,7 \% dos trabalhos não relataram as dificuldades enfrentadas durante o desenvolvimento das atividades. Isso pode ser atribuído a duas razões: ou os autores não verificaram 
de fato grandes problemas na condução das propostas, não necessitando descrevê-las; ou eles optaram por não dar destaque a essas questões no trabalho, procurando, por outro lado, discutir com mais detalhes os pontos positivos da proposta.

Tabela 8 - Dificuldades mencionadas pelos autores nos trabalhos que reportam o uso de TDC em sala de aula.

\begin{tabular}{|c|c|c|}
\hline $\begin{array}{l}\text { Dificuldade na aplicação das } \\
\text { atividades }\end{array}$ & Número do trabalho & $\%$ \\
\hline $\begin{array}{l}\text { Dificuldades dos alunos na } \\
\text { leitura e interpretação }\end{array}$ & $1,4,6,11,13,17$ & 28,6 \\
\hline $\begin{array}{l}\text { Incompreensão de termos } \\
\text { científicos específicos }\end{array}$ & $1,2,3,11,14,17$ & 28,6 \\
\hline $\begin{array}{l}\text { Pouco tempo para aplicação das } \\
\text { atividades }\end{array}$ & 7 & 4,8 \\
\hline Não descreve & $\begin{array}{c}5,8,9,10,12,15,16,17,18,19 \\
20,21,22,23\end{array}$ & 66,7 \\
\hline
\end{tabular}

(Fonte: autores)

Dentre as dificuldades mencionadas, as que mais se destacaram foram aquelas relacionadas à leitura e interpretação dos textos $(28,6 \%)$ e a incompreensão de termos científicos específicos presentes nos TDC (28,6\%).

Guerra e Menezes (trabalho no 6) relataram que os alunos apresentaram uma resistência inicial com relação à atividade devido à dificuldade que tinham em entender porque leriam um texto em uma aula de Física. Silva e Kawamura (trabalho no 1) também relatam em sua proposta que inicialmente houve

certa "recusa" dos alunos em aderir à leitura dos TDC. Os alunos, de forma geral, preferiam textos mais curtos e pareciam possuir um certo "preconceito" quanto à atitude de ler - para eles, trata-se de algo "chato" e "desinteressante". (SILVA; KAWAMURA, 2001, p.330).

Nessa atividade realizada com alunos do EM sobre a natureza da luz, as autoras constataram determinado grau de dificuldade para se trabalhar a leitura de TDC em sala de aula, pois os alunos não estão habituados com textos dessa natureza.

Silva e Almeida (trabalho no 11) também identificaram problemas dessa natureza e, dessa forma, indicaram a urgência em se trabalhar nas escolas mais propostas que envolvam diferentes tipos de leitura, inclusive nas disciplinas de ciências naturais, a fim de promover o interesse dos alunos. Porém,

mesmo um texto cujo tema seja de interesse para boa parte dos estudantes pode contribuir para afastá-los da leitura. Aparentemente, isso pode ocorrer se ao efetuá-la houver grande dificuldade em sua interpretação, ou seja, em produzir sentidos a partir da leitura do texto. (SILVA; ALMEIDA, 2013, p. 66)

Isso foi observado por Monteiro et al. (trabalho no 2) em uma atividade utilizando textos de revistas de DC em sala de aula. Alguns alunos apresentaram desestímulo em realizar as leituras durante as atividades devido à dificuldade de compreensão decorrente, sobretudo, do vocabulário utilizado. Por outro lado, os autores reportam que, mediante discussões em grupo na sala de aula e com o 
auxílio do professor, a leitura se tornava mais fluída e interessante. Loiola et al. (trabalho no 13) também descreveram a dificuldade de interpretação dos textos por parte de alguns alunos da EJA, pois estes, mesmo com adaptações do artigo e com a mediação do professor, apresentaram problemas na compreensão das ideias abordadas no texto.

Teixeira Júnior e Silva (2007) apontam a baixa compreensão de leitura dos estudantes, a pouca valorização da atividade de leitura no ensino de Ciências, a desmotivação dos alunos e as dificuldades por eles enfrentadas ao lerem textos científicos, como fatores preocupantes no ensino. Por isso, é importante que as habilidades de leitura e escrita sejam trabalhadas em diversas disciplinas, uma vez que os estudantes, inclusive, apresentam dificuldades de interpretar questões e problemas de Física, Química e Matemática, devido às deficiências na interpretação de enunciados (FRANCISCO JUNIOR et al., 2008).

Enquanto estudos como os apresentados acima apontaram dificuldades associadas as atividades de leituras em sala de aula, Santos e Zanotello (trabalho no 14) assinalam que os termos técnicos ligados à Biologia foram obstáculos para alguns estudantes: enquanto alguns recorreram à internet para sanar as dúvidas, outros não tiveram essa iniciativa, esperando que a professora as explicasse. Silva e Almeida (trabalho no 17) apontam que os termos científicos, assim como os altos níveis de densidade conceitual somados aos baixos níveis de didaticidade e laicidade do TDC podem causar o desinteresse do aluno pela leitura.

Dessa forma, textos com alta densidade discursiva - momentos em que a linguagem científica se sobressai - geralmente são acompanhados de recursos explicativos que buscam deixar a leitura mais compreensível ao leitor. Isso foi verificado, por exemplo, por Ferreira e Queiroz (2012b) ao analisar artigos da revista Ciência Hoje, apresentando a nomeação e a descrição como características identificadas nesses textos que possibilitam uma melhor compreensão dos aspectos de cientificidade apresentados.

Por fim, 4,8 \% dos trabalhos discutiram as dificuldades relacionadas ao pouco tempo para a realização das atividades. Perticarrari et al. (trabalho no 7) apontaram que as condições de trabalho, bem como o pouco tempo para a realização das atividades podem interferir no resultado final. Dessa forma, afirmaram que o professor com um tempo maior na disciplina e com planejamento adequado pode alcançar resultados promissores em propostas dessa natureza.

Vale ressaltar que essas dificuldades apenas mostram e delimitam caminhos. Indicam, por exemplo, alguns cuidados a serem adotados ao se desenvolver atividades dessa natureza, como o de verificar o tempo disponível e conferir se a densidade do texto está de acordo com o nível de ensino. Além disso, o fato dos alunos apresentarem, inicialmente, algumas resistências ou dificuldades, não significa que será sempre assim. Segundo Bertoldo et al (2015),

mesmo não sendo um interesse geral dos estudantes a leitura de revistas de divulgação científica, é possível considerar que muitos podem não se interessar porque não chegaram a ter conhecimento desse tipo de revista, visto que esse gênero não está ainda "enraizado" na cultura da população brasileira (BERTOLDO et al., 2015, p.324). 


\title{
CONSIDERAÇÕES FINAIS
}

Segundo Almeida (2010), algumas características dos textos de divulgação científica favorecem seu uso como recurso mediador do discurso escolar relativo à ciência, uma vez que

\begin{abstract}
grande parte deles apresenta uma linguagem razoavelmente próxima à linguagem de quem frequenta a escola, à linguagem cotidiana do estudante; em muitos deles a linguagem se aproxima da linguagem literária, ainda que parcialmente; muitos incluem textos em quadrinhos e/ou comentários humorísticos; de muitos deles fazem parte aspectos da biografia dos cientistas que produziram os conhecimentos a que estão se referindo e/ou fatos históricos associados à produção daqueles conhecimentos; outros incluem não só o conhecimento em si e aspectos da sua produção, mas também algumas de suas consequências para a sociedade, ou mesmo apontam quais fatos sociais contribuíram para a produção do conhecimento científico a que se referem (ALMEIDA, 2010, p. 21).
\end{abstract}

Tais aspectos podem ter contribuído para que, nos últimos anos, esses materiais venham sendo objeto de estudo nas pesquisas da área de educação em ciências. A maioria dessas pesquisas, conforme apontado Ferreira e Queiroz (2012a), tem como foco a seleção, caracterização e análise de TDC. Por outro lado, conforme evidenciamos no levantamento que realizamos em revistas da área de ensino de ciências e nas atas do ENPEC, as pesquisas sobre sua aplicação em aulas de ciências na educação básica têm crescimento ainda muito tímido, revelando, portanto, a necessidade de mais estudos nessa linha.

Quanto ao contexto de aplicação das atividades didáticas, observamos que a maioria delas é desenvolvida em escolas da rede pública, possivelmente devido a um maior acesso dos pesquisadores a este espaço educativo para realização das propostas. As atividades são aplicadas em sua maioria no Ensino Médio, uma vez que nele são trabalhadas disciplinas como Física, Biologia e Química, as quais se articulam mais facilmente à temática dos TDC. Dentre as disciplinas do Ensino Médio, a Física foi aquela na qual se observou um maior percentual de atividades desenvolvidas. Por outro lado, identificamos apenas um trabalho desenvolvido em sala de aula de Química, revelando uma lacuna dentre as pesquisas que propõem analisar as possibilidades de uso de TDC em disciplinas da educação básica.

Também buscamos analisar com que objetivos didáticos as propostas envolvendo o uso de TDC foram desenvolvidas. Assim, observamos nos trabalhos que a maioria das atividades foi realizada com a intencionalidade de favorecer a aprendizagem de conceitos científicos. Além desse, mas em menor percentual, os autores também explicitaram objetivos como desenvolver habilidades de leitura e interpretação, despertar curiosidade ou ainda favorecer a argumentação dos alunos. Cabe destacar que, embora os textos divulgação científica sejam apontados como materiais capazes de veicular concepções de ciência, em alguns casos inadequadas (CARDOSO et al., 2015), poucas atividades tiveram como foco discutir aspectos da natureza da ciência. Isso evidencia que tal questão necessita ser mais explorada, tanto por pesquisadores quanto por professores em sala de aula.

Com relação às estratégias didáticas adotadas nas atividades, além da leitura do texto - embora não explicitada pelo autor, mas presente em todos os 
trabalhos -, verificou-se também que houve uma expressiva preocupação em aplicar questionários, tanto para o levantamento de conhecimentos prévios dos estudantes sobre os temas abordados nos TDC, quanto para avaliar o que foi aprendido por eles após as tarefas. Esses dados revelam que o uso do TDC no contexto escolar está muito associado à possibilidade de favorecer a construção de conceitos científicos em sala de aula. Ademais, muitas atividades adotaram discussões e debates com base no conteúdo do TDC, possibilitando a reflexão sobre vários aspectos de natureza social. A produção de outros gêneros textuais foi pouco explorada nessas atividades.

Dentre os diversos tipos de TDC, os textos oriundos de revistas de divulgação científica foram os mais explorados, sobretudo devido à maior facilidade de acesso a tais materiais, quando comparados a livros de divulgação científica, por exemplo. As revistas Ciência Hoje e Superinteressante foram as mais utilizadas em tais propostas.

Na perspectiva dos autores, e com base nos dados por eles apresentados, a maioria das atividades contribuiu para favorecer a aprendizagem de conceitos, o que é coerente com o principal objetivo didático citado nos trabalhos. Além disso, alguns autores mencionaram que as discussões pautadas nos TDC podem ser úteis para identificar concepções alternativas dos alunos. $O$ desenvolvimento de habilidades de leitura e a melhoria da capacidade de argumentação também foram contribuições observadas em várias propostas. Alguns trabalhos também mencionaram como contribuição a apropriação conhecimentos sobre a natureza da ciência pelos alunos, embora em muitos desses trabalhos esta questão não tenha sido apontada inicialmente como um objetivo a ser alcançado na atividade.

Além das contribuições indicadas nos trabalhos, foi possível verificar que algumas dificuldades atribuídas ao uso do TDC em sala de aula foram apontadas pelos autores. Dentre elas estão: o tempo necessário para o desenvolvimento das atividades; a linguagem e termos científicos que não fazem parte do cotidiano do aluno; e a dificuldade dos alunos em ler e interpretar os textos, seja devido à falta de interesse, à falta do hábito de leitura ou ao desestímulo devido ao vocabulário científico.

Portanto, a análise dos trabalhos selecionados para este estudo nos possibilitou identificar algumas características de atividades que utilizam o TDC como um recurso didático em sala de aula da educação básica. Embora esta pesquisa não tenha abarcado a análise de teses e dissertações, bem como os eventos específicos de cada área (ensino de química, ensino de biologia etc.), consideramos que as fontes selecionadas (atas do ENPEC e 22 revistas) nos possibilitaram obter dados representativos a respeito das pesquisas envolvendo o uso de TDC em sala de aula. Por outro lado, trabalhos do tipo relato de experiência, muitos deles mais presentes nos eventos específicos de cada área, não puderam ser analisados devido ao recorte realizado neste estudo. Dessa forma, aponta-se para a necessidade de um levantamento que abarque a análise de trabalhos dessa natureza em anais dos eventos de áreas específicas do ensino de ciências.

Por fim, ressaltamos que os resultados desta pesquisa podem ser úteis a pesquisadores da área, interessados em conhecer o perfil das pesquisas desenvolvidas nesse contexto e suas eventuais lacunas, e também aos professores, uma vez que, por meio de tal mapeamento, é possível localizar 
trabalhos desenvolvidos no contexto de sua disciplina ou com objetivos que atendam às suas perspectivas de ensino. Esse mapeamento possibilita também conhecer algumas estratégias comumente associadas à leitura de TDC, bem como as dificuldades enfrentadas por outros professores na implementação de propostas dessa natureza. 


\title{
The use of popular science texts in didactic activities: a review
}

\begin{abstract}
In this paper we present a literature review of works developed in the science education area that report the use of popular science texts in didactic activities applied in the Elementary and High School classroom. The state-of-the-art research was carried out in the annals of the Encontro Nacional de Pesquisa em Educação em Ciências and in national periodicals of the science education area, covering a period of 20 years. We have analyzed in the works the following aspects: contexts of application of the activities (level of education, subjects); educational objectives of the activities; kinds of popular science texts e didactic strategies used in them; main contributions of the activities reported by the authors. We have observed that most of the didactic activities use texts from popular science magazines, applying as didactic strategies the reading and discussion; stimulating reading and argumentation skills, and scientific concepts learning.
\end{abstract}

KEYWORDS: Popular science text. Didactic activities. Literature review. 
1 A fim de reduzir a extensão do artigo e, considerando que o leitor já tem acesso às principais informações sobre os trabalhos no Quadro 1, optou-se por apenas mencionar, ao longo da análise dos dados, o número atribuído a cada um dos trabalhos e, com isso, não apresentá-los na lista de referências bibliográficas.

\section{REFERÊNCIAS}

ALMEIDA, M. J. P. M. de. O texto de divulgação científica como recurso didático na mediação do discurso escolar relativo à Ciência. In: PINTO, G. A. Divulgação científica e práticas educativas. Curitiba: Editora CRV, 2010.

ALMEIDA, S. A.; GIORDAN, M. A revisa Ciência Hoje das Crianças no letramento escolar: a retextualização de artigos de divulgação científica. Educação e Pesquisa, v.40, n. 4, p. 999-1014, 2014.

ALTARUGIO, M. H.; DINIZ, M. L.; LOCATELLI, S. W. O debate como estratégia em aulas de química. Química Nova na Escola, v. 32, n. 1, p. 26-30, 2010.

AMORIM, L. H.; MASSARANI, L. Jornalismo Científico: um estudo de caso de três jornais brasileiros. Revista Brasileira de Ensino de Ciência e Tecnologia, v. 1, n. 1, p.73-84, 2008.

BARDIN, L. Análise de Conteúdo. Lisboa: Edições 70, 2008.

BERTOLDO, R. R.; CUNHA, M. B.; STRIEDER, D. M.; SILVA, A. S. Momentos de leitura na escola: tem ciência? In: GIORDAN, M.; CUNHA, M. B. (orgs). Divulgação científica na sala de aula: perspectivas e possibilidades. ljuí: Editora Unijuí, 2015. p. 307-329.

CARDOSO, D.; NORONHA, A.; WATANABE, G.; GURGEL, I. Texto Jornalístico sobre Ciência: uma análise do discurso sobre a natureza da ciência. Alexandria - Revista de Educação em Ciência e Tecnologia, v.8, n.3, p.229-251, 2015.

CAVALCANTE, A. A. R. S.; FARIAS, M. F. V. S. Impresso x Digital: uma análise das transformações do jornalismo de revista a partir das Revistas Canal.com e Bezouro. In: CONGRESSO DE CIÊNCIAS DA COMUNICAÇÃO NA REGIÃO NORDESTE, 13, 2011. Atas... Maceió, 2011. 
FERREIRA, L. N. A.; QUEIROZ, S. L. Características discursivas de artigos de divulgação científica relacionados à química. Revista Electrónica de Enseñanza de las Ciencias, v. 11, n. 1, p. 21-42, 2012b.

FERREIRA, N. S. A. As pesquisas denominadas "Estado da Arte". Educação \& Sociedade, n. 79, p. 257-272, 2002.

FRANCISCO JUNIOR, W. E. Estratégias de leitura na educação química e na formação docente: necessidades e contribuições de um planejamento crítico. 2011. 185 f. Tese (Doutorado em Química) - Universidade Estadual Paulista, Instituto de Química de Araraquara, 2011.

FRANCISCO JUNIOR, W. E.; SILVA, D. M.; NASCIMENTO, R. C. F.; YAMASHITA, M. O teatro científico como ferramenta para a formação docente: uma pesquisa no âmbito do PIBID. Revista Brasileira de Pesquisa em Educação em Ciências, v. 14, n.3, p. 79-100, 2014.

FRANCISCO JUNIOR, W.E.; FERREIRA, L.H. e HARTWIG, D.R. A dinâmica de resolução de problemas: analisando episódios em sala de aula. Ciências \& Cognição, v. 13, p. 82-99, 2008.

GIL-PEREZ, D.; MONTORO, I. F.; ALÍS, J. C.; CACHAPUZ, A.; PRAIA, J. Para uma imagem não deformada do trabalho científico. Ciência \& Educação, v.7, n.2, p.125-153, 2001.

GIRALDI, P. M.; CASSIANI, S. Leitura em aulas de ciências: análise de condições de produção. In: ENCONTRO NACIONAL DE PESQUISA EM EDUCAÇÃO EM CIÊNCIAS, 7, 2009. Atas.... Florianópolis, 2009.

GOMES, L. C.; FUSINATO, P. A.; NEVES, M. C. D. Análise da relação entre força e movimento em uma revista de divulgação científica. Ciência \& Educação, v. 16, n. 2, p. 341-353, 2010.

GOUVÊA, G. A divulgação científica para crianças: o caso da Ciência Hoje das Crianças. 2000. Tese (doutorado) - Universidade Federal do Rio de Janeiro, 2000.

GUERRA, A.; MENEZES, A. M. S. Literatura na Física: uma possível abordagem para o ensino de ciências? In: ENCONTRO NACIONAL DE PESQUISA EM EDUCAÇÃO EM CIÊNCIAS, 7, 2009. Atas.... Florianópolis, 2009. 
MARANDINO, M. Educação em museus: a mediação em foco. São Paulo: Greenf/ FEUSP, 2008.

MARANDINO, M. Interfaces na relação museu-escola. Caderno Catarinense de Ensino de Física, v. 18, n.1, p.85-100, 2001.

MARTINS, I.; CASSAB, M.; ROCHA, M. B. Análise do processo de re-elaboração discursiva de um texto de divulgação científica para um texto didático. In: ENCONTRO NACIONAL DE PESQUISA EM EDUCAÇÃO EM CIÊNCIAS, 3, 2001. Atas... Atibaia, SP, 2001.

NASCIMENTO, T. G.; REZENDE JUNIOR, M. F. A produção sobre divulgação científica na área de educação em ciências: referenciais teóricos e principais temáticas. Investigações em Ensino de Ciências, v. 15, n. 1, p. 97-120, 2010.

OLIVEIRA, J. R. S. A dinâmica da ciência em artigos de divulgação científica da revista Pesquisa FAPESP. In.: ENCONTRO NACIONAL DE PESQUISA EM EDUCAÇÃO EM CIÊNCIAS, 9, 2013. Atas... Águas de Lindóia, SP, 2013.

PUIATI, L. L; BOROWSKI, H. G; TERRAZZAN, E. A. O texto de divulgação científica como recurso para o ensino de ciências na educação básica: um levantamento das produções nos ENPEC. In: ENCONTRO NACIONAL DE PESQUISA EM EDUCAÇÃO EM CIÊNCIAS, 6., 2007. Anais ..., Florianópolis, 2007.

RIBEIRO, R. A.; M. R. D., KAWAMURA. Divulgação Científica para o público infantil: potencialidades da revista Ciência Hoje das Crianças. In: XIX SIMPÓSIO NACIONAL DE ENSINO DE FÍSICA, 19, 2011. Atas... Manaus, 2011.

ROCHA, M. B. Contribuições dos textos de divulgação científica para o ensino de Ciências na perspectiva dos professores. Acta Scientiae, v.14, n.01, p. 132-150, 2012.

ROMANOWSKI, J. P.; ENS, R. T. As pesquisas denominadas do tipo "Estado da Arte" em educação. Diálogo Educacional, v. 6, n.19, p. 37-50, 2006.

SASSERON, L. H.; CARVALHO, A. M. P. Uma análise de referenciais teóricos sobre a estrutura do argumento para estudos de argumentação no ensino de ciências. Revista Ensaio, v. 13, n. 03, p. 243-262, 2011. ressonância magnética no Ensino Médio. In: ENCONTRO NACIONAL DE PESQUISA EM EDUCAÇÃO EM CIÊNCIAS, 9, 2013. Atas... Águas de Lindóia, 2013. 
SILVA, J. A.; KAWAMURA, M. R. D. A Natureza da Luz: uma atividade com textos de divulgação científica em sala de aula. Caderno Catarinense de Ensino de Física, v. 18, n. 3: p. 316-339, ago. 2001.

TEIXEIRA JÚNIOR, J. G. e SILVA, R. M. G. Perfil de leitores em um curso de Licenciatura em Química. Química Nova, v. 30, n. 5, p. 1365-1368, 2007.

ZAMBONI, L. M. S. Cientistas, jornalistas e a divulgação científica: subjetividade e heterogeneidade no discurso da divulgação científica. Campinas: Autores Associados, 2001. 167 p.

ZANETIC, J. Literatura e Cultura Científica. In: ALMEIDA, M.J.P.M. e SILVA, H.C. (orgs.). Linguagem, leituras e ensino de ciências. Campinas: Mercado das Letras, 1998. p. 11-36.

Recebido: 2017-06-12

Aprovado: 2017-10-29

DOI: $10.3895 /$ rbect.v11n3.6002

Como citar: BATISTELE, M. C. B.; DINIZ, N. P.; OLIVEIRA, J. R. S. O uso de textos de divulgação científica em atividades didáticas: uma revisão. Revista Brasileira de Ensino de Ciência e Tecnologia, v. 11, n. 3, 2018. Disponível em: <https://periodicos.utfpr.edu.br/rbect/article/view/6002>. Acesso em: xxx. Correspondência: Jane Raquel Silva de Oliveira - janeraquel@unifei.edu.br Direito autoral: Este artigo está licenciado sob os termos da Licença Creative Commons-Atribuição 4.0 Internacional. 